Nunt. Antiquus, Belo Horizonte, v. 17, n. 1, p. 85-106, 2021

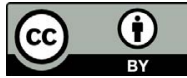

\title{
A nova filosofia da natureza de Francis Bacon como apropriação e ressignificação da física aristotélica
}

\author{
The New Philosophy of Nature by Francis Bacon as \\ Appropriation and Reframing of the Aristotelian Physics
}

\author{
Adriel Fonteles de Moura \\ Universidade Federal do Paraná (UFPR), Curitiba, Paraná / Brasil \\ adriel.fonteles@yahoo.com \\ https://orcid.org/0000-0003-3923-9388
}

Resumo: A função deste artigo é investigar a influência do aristotelismo na nova filosofia da natureza do pensador e cientista inglês Francis Bacon, tendo como pano de fundo a obra Novum Organum, publicada no ano de 1620. Em algumas etapas desta obra, Francis Bacon pretende fazer uma apropriação e uma ressignificação de conceitos importantes do aristotelismo, como forma e natureza. Apropriação, pois o paradigma da forma e da natureza enquanto princípios dos seres são retomados por Francis Bacon e constituem pilares importantes do Novum Organum. Ressignificação, visto que Francis Bacon era um grande crítico do aristotelismo como método de conhecer a natureza; o filósofo produziu novas maneiras de aplicar os conceitos do aristotelismo no contexto científico da modernidade. No geral, uma das ideias principais desta obra é apresentar questionamentos e críticas aos aspectos centrais da filosofia de Aristóteles, como os processos predominantemente formais do conhecimento, que acabam por oferecer pouco ou nenhum recurso para as descobertas e invenções no âmbito das ciências naturais. Mas, para além das críticas, a ideia deste artigo será delinear a influência aristotélica presente no Novum Organum, apesar da recusa baconiana ao aristotelismo como método de conhecimento da natureza.

Palavras-chave: filosofia da natureza; filosofia da ciência; Aristóteles; Francis Bacon.

Abstract: The aim of this article is to investigate the influence of the aristotelism in the new philosophy of nature from the English thinker and scientist Francis Bacon, having as background the piece of work Novum Organum Published in 1620. At some points of this specific piece of work, Francis Bacon intends to do na appropriation and 
give a new meaning to relevant concepts of the aristotelism itself. Such as form and nature. Appropriation; since the paradigm of form and nature, while principle of the beings, is revisited by Francis Bacon and consists of important pillars of the Novum Organum. By new meaning, since Francis Bacon was a strong critic of the aristotelism as a method of getting to know nature, this philosopher produced new ways of applying the concepts of the aristotelism in the scientific context of modernity. In general, one of the most important ideas of this piece of work is to present questions and criticism to the central aspects of Aristoteles' philosophy. As well as the mainly formal processes of knowledge, that offer a little or no resource to discoveries and inventions in the field of natural Sciences. Although beyond critic, the Idea of this article will be to outline the influence of Aristoteles in the Novum Organum. Despite Bacon's refusal to the aristotelism as a method acknowledging nature.

Keywords: philosophy of nature; philosophy of science; Aristoteles; Francis Bacon

\section{A conjugação da natureza com o fazer e pensar humano no método científico baconiano}

$\mathrm{Na}$ esfera do conhecimento científico, uma das características do pensamento moderno se define de acordo com uma nova forma de se fazer ciência, baseada no experimento controlado pelo homem para a compreensão dos fenômenos da natureza (ZATERKA, 2012, p. 681). Este novo paradigma, que começou a ser consolidado em meados do século XVI a início do século XVII, se fundamenta na tentativa de manejo do homem sobre a natureza através da possibilidade de arranjar e rearranjar os seus compostos por meio de procedimentos empíricos, diz Luciana Zaterka (2012, p. 682):

A ciência, de agora em diante, será conduzida pelo homem da ciência, entendido como "ministro e intérprete da natureza", isto é, preocupado com um conhecimento que vincula o saber teórico com o âmbito prático e operacional, este último norteado pela sua utilidade e proveito para o bem-estar da maioria.

Certamente, um dos marcos para a mudança de paradigma na ciência, no período da modernidade, foi o filósofo e cientista inglês Francis Bacon (1561-1626). 
Esta mudança se deve, antes de tudo, à crítica baconiana a uma tradição filosófica da natureza da antiguidade, fundamentada na recusa da tradição em atribuir um papel social e amplamente professoral ao saber - visto que as diferentes filosofias da antiguidade estavam limitadas a círculos sociais e seitas restritas à participação de um pequeno público. Bacon, deste modo, executa um movimento contrário à soberba intelectual dos antigos e escolásticos (ROSSI, 2006, p. 169). Por outro lado, a concepção baconiana de ciência tinha a utilidade e o bem-estar geral como finalidades, tomando como base os limites do ser humano em conhecer a natureza em sua totalidade (ZATERKA, 2012, p. 682). Uma de suas principais obras de divulgação deste novo procedimento científico é o Novum Organum, publicado em 1620.

A epistemologia baconiana sugere uma concatenação entre a parte prática e a parte teórica do conhecimento, isto é, não basta apenas conhecer as causas dos fenômenos da natureza, mas também conhecer os efeitos práticos decorrentes da intervenção humana nela, de acordo com Luciana Zaterka (2012, p. 683): “O pensador propõe, então, algo inovador: trocar os livros pela natureza, a biblioteca pelo laboratório, acreditando que o homem deva desvencilhar-se da metafísica escolástica ${ }^{1}$

\footnotetext{
${ }^{1}$ Bacon não lutava apenas contra alguns aspectos dogmáticos presentes na filosofia de Aristóteles, mas também lutava contra ao que Paolo Rossi denomina de ditadura cultural do aristotelismo (2006, p. 170). Esta ditadura, iniciada pelo próprio Aristóteles, se estendeu na mentalidade escolástica no Medievo: "Ao apresentar a si próprio como o ápice ou a culminação da história do pensamento, Aristóteles falseou a possibilidade de compreensão do pensamento antigo e apresentou-se como o homem capaz de dominar ao mesmo tempo o passado e o porvir. Nesta obra de falseamento ele foi ajudado pelas invasões dos bárbaros, que abalroaram a cultura humana e obrigaram os monges da Idade Média (aos quais, depois do naufrágio geral, só haviam restado as dele e de outros pouquíssimos) a acabar aprisionando suas mentes dentro das obras dele, assim como haviam aprisionado seus corpos dentro das celas dos conventos" (ROSSI, 2006, p. 170-171). Além disso, o modelo central da escolástica que Francis Bacon utiliza como mote para a interpretação da filosofia aristotélica é a crença nas entidades transcendentes e abstratas da matéria, pautada por um dualismo radical entre forma e matéria, corpo e espírito humanos (ROSSI, p. 176). No sistema científico baconiano, a metafísica escolástica é considerada como uma mistura de religião e ciência que, por consequência, acaba por corromper uma e outra.
} 
e voltar-se para os eventos da natureza". Logo, o ponto-chave do conhecimento científico na filosofia de Francis Bacon é uma substituição parcial do caráter contemplativo e intelectivo das ciências pelo caráter prático, mas sem deixar de lado a reflexão sobre os processos e efeitos decorrentes da experiência científica.

No início do Novum Organum, Francis Bacon faz uma circunscrição dos limites do conhecimento humano (I, I, p. 13). Enquanto sujeito de um novo modelo de conhecimento científico, Bacon o define como um modelo de sujeito que "[...] faz e entende tanto quanto constata, pela observação dos fatos ou pelo trabalho da mente, sobre a ordem da natureza; não sabe nem pode mais" (1979, p. 13). Esta definição leva em consideração apenas o homem em seu pensar e fazer científico, enquanto espécie que é capaz de compreender os processos e as operações da natureza a partir da observação empírica e através da intelecção. Neste caso, Bacon acredita que só podemos ter conhecimento dos processos naturais pela associação da mão com o intelecto (I, II, p. 13). Metaforicamente, a mão corresponde ao fazer mecânico, necessário para a manipulação no campo da experimentação científica. Por sua vez, o intelecto seria um instrumento interno ao homem de compreensão da experiência científica e de interpretação da natureza.

É interessante prestarmos atenção nesta conjunção entre a operação mecânica e a operação intelectual que circunscreve a definição do homem baconiano, pois é nestes aspectos que se observa o poder que o homem teria sobre a ordem da natureza, poder este centrado em seu caráter produtivo. $\mathrm{O}$ homem não teria apenas a capacidade de compreender e interpretar os processos naturais, mas também de interferir nestes processos por meio de seu conhecimento. No entanto, isto não quer dizer necessariamente que haja simplesmente um mando ou domínio sobre a natureza, segundo Bacon: "Ciência e poder do homem coincidem, uma vez que, sendo a causa ignorada, frustra-se o efeito. Pois a natureza não se vence, se não quando se lhe obedece" (Novum Organum, I, III, p. 13). Mais uma vez, Francis Bacon coloca em evidência os traços característicos do homem do fazer científico, unindo a sua capacidade de conhecer com o fazer operativo a partir do exercício 
desta capacidade. No âmbito da relação entre o humano e a natureza, Bacon sugere que é impossível o homem exercer pleno domínio sobre a natureza, mas lhe é atribuído o poder de modificar alguns dos seus aspectos, através da prática do que foi compreendido intelectualmente acerca dos fenômenos naturais.

No Livro I, Aforismo LI do Novum Organum, Bacon (1979, p. 26) pontua algumas tendências próprias do intelecto humano. Numa destas pontuações, a mais importante é, certamente, a tendência do intelecto em realizar abstrações, ou seja, criar formas fictícias que não condizem tacitamente com os processos naturais. Por esta razão, Bacon (1979, p. 26) adverte que "[...] é melhor dividir em partes a natureza que traduzila em abstrações". Nesta empresa de dividir a natureza em partes está a consideração do privilégio da matéria sobre a forma pura e abstrata. $\mathrm{Na}$ linguagem baconiana, a matéria seria o conceito central dos processos naturais, abarcando essencialmente, "[...] os seus esquematismos, os metaesquematismos, o ato puro, e a lei do ato, que é o movimento" (BACON, 1979, p. 26). Considerando que tudo o que compõe a natureza é material, tudo que está subsumido a ela está sujeito a algum tipo de processo de mudança, ocasionado pelo movimento que, strictu sensu, é o princípio de mudança nos corpos. Ora, mesmo que, por outro lado, Bacon seja um crítico à concepção escolástica e aristotélica de forma enquanto produto da abstração intelectual, ele ainda aceita uma das acepções do termo: "As formas são simples ficções do espírito humano, a não ser que designemos por formas as próprias leis do ato" (BACON, 1979, p. 26). Esta forma nada seria mais do que uma máxima que vale para todo e qualquer processo natural, a saber, as leis do movimento e do ato que se verificam nos acontecimentos naturais. A teoria da natureza de Bacon, portanto, parte de uma teoria da forma enquanto lei do ato e das operações no âmbito natural. 


\section{A doutrina aristotélica das causas ${ }^{2}$ na teoria da natureza de Francis Bacon}

Ora, mas fora a necessidade absoluta da mudança e do movimento que rege todos os fenômenos naturais, não haveria na filosofia baconiana nada que assegurasse um sustentáculo fixo, aos moldes da metafísica, no plano epistemológico da concepção de natureza? Bacon não deixa de se preocupar com esta questão, ao dizer que (Novum Organum, II, III, p. 94):

[...] quem conhece apenas a causa eficiente e a causa material (que são causas instáveis e não são mais que veículos que em certos casos provocam a forma), esse pode chegar a novas descobertas em matéria algo semelhante e para isso preparada, mas não conseguir mudar os limites mais profundos e estáveis das coisas.

O que seriam estes limites mais profundos e estáveis das coisas, que subjazem perenemente no solo da alteração e instabilidade da multiplicidade material na natureza? Para Bacon, somente o conhecimento das formas pode garantir o acesso à unidade da natureza, que contém em si a diversidade, a dinâmica e a pluralidade material. Por conseguinte, aí entra a causa formal como parte fundamental do conhecimento científico. No entanto, Francis Bacon (1979, p. 94-95) afirma na sequência uma característica peculiar a respeito do sujeito que presa o conhecimento das formas, segundo ele, este sujeito "[...] pode descobrir e provocar o

\footnotetext{
${ }^{2}$ Para investigar as principais causas dos fenômenos da natureza, Aristóteles lança mão da doutrina das quatro causas, apresentadas na Física II, 3 e na Metafísica I, 3. Para Aristóteles, em sentido amplo, o conhecimento das coisas tem por critério o conhecimento do "porquê" das coisas ou, melhor dizendo, de sua causa próxima. A causa próxima pode ser material, formal, eficiente e final. Expliquemos, em termos básicos, o que cada causa representa. A causa é material quando se trata a respeito do que algo é feito. A causa é formal quando se trata da forma ou modelo de algo, podendo ser a definição da coisa dada através do gênero em que ela pertence. A causa é eficiente quando se trata do tipo de movimento ou de processo que resultou em algo. A causa é final quando se trata a respeito daquilo para o qual algo existe. Uma mesma coisa e um mesmo acontecimento, para Aristóteles, pode comportar em si os quatro sentidos de causa (Física II, 3, p. 140-5 e Metafisica I, 3, p. 15-19).
} 
que até agora não se produziu, nem pelas vicissitudes naturais, nem pela atividade experimental, nem pelo próprio acaso e nem sequer chegou a ser cogitado pela mente humana". Se for ver a forma por este ângulo, ela se coloca para além das operações naturais, experimentais e intelectuais, como se os limites mais profundos e estáveis das coisas não pudesse ser inteligido e experienciado, mas, ao mesmo tempo, pudesse ser condição para um pensar e um fazer num âmbito que foge à ordinariedade da natureza, como se o homem tivesse de operar sobre si mesmo e sobre a natureza para atingir o conhecimento de tais limites.

Na leitura de G. Ysselmuiden (1906, p. 18), Francis Bacon crê que o verdadeiro saber é subsumido à doutrina das causas e à relação com a pesquisa científica das formas naturais. Porém, exceto no âmbito das ciências morais, a causa final é eliminada do progresso das ciências. Sobrando as causas material, formal e eficiente, Ysselmuiden (1906, p. 19) classifica em dois pares: enquanto as causas material e eficiente são "variáveis e particulares", a causa formal é eterna. Para explicar esta importante diferenciação entre as causas no pensar e fazer científico, o autor lança mão de um exemplo: "[...] o fogo - causa eficiente - produz a dureza quando exerce a sua causalidade sobre o lodo. Ao contrário, ele é causa de liquefação, quando interage com a cera, como matéria. A forma da dureza torna dura uma matéria qualquer, que se trata da cera ou do lodo" (YSSELMUIDEN, 1906, p. 19. Tradução nossa). Neste caso, podemos resumir que a causa material e eficiente estão mais ligadas ao processo de transformação de um estado da matéria. $\mathrm{O}$ âmbito conceitual da própria matéria permite que haja a mudança, efetivada por alguma causa eficiente. A causa formal, por outro lado, tem um papel descritivo, de nos fazer revelar o aspecto de algo, resultante da causa eficiente sobre a causa material.

No entanto, não basta concebermos a forma como pura e simplesmente um aspecto descritivo que diz respeito à organização atual dos corpos. Como é um conceito derivado da metafísica e é replicado ao advento científico da modernidade, Ysselmuiden (1906, p. 19) vê a necessidade de desambiguizá-lo através da distinção entre duas espécies de forma no sistema científico baconiano. Em primeiro lugar, as formas 
são compostos naturais simples, pode ser uma rosa, um leão, a água e o ar. Em segundo lugar, as formas são princípios dos compostos naturais simples, são as qualidades corretamente atribuídas a um estado da matéria natural, por exemplo, o denso, o quente, o alto, o tangível, etc. Os corpos concretos do mundo sensível, por sua vez, representam a combinação da forma com um composto natural simples e o princípio deste composto, diretamente coligado com a causa material e eficiente ou, conforme conclui Ysselmuiden (1906, p. 19): "Cada composto natural encerra uma multiplicidade de formas simples". Mas quais são os pressupostos de Francis Bacon para engendrar um novo conceito de forma na esfera do conhecimento científico?

\section{Diferenças e semelhanças entre as concepções de filosofia natural aristotélica e baconiana}

Para entendermos um pouco mais destes avanços e recuos que Bacon faz em relação ao conceito de forma e a relação formal que o sujeito científico tem com a natureza, precisamos fazer um salto retrospectivo para entender este conceito. Dentre tantas coisas abordadas na filosofia de Francis Bacon a despeito do modo antigo de se pensar cientificamente, o paradigma aristotélico de forma é altamente criticado pelo filósofo, por serem consideradas como fiç̧ões do espírito humano, de acordo com que vimos acima. Nos estudos da antiguidade sobre a natureza, a palavra forma (eidos) designa o aspecto externo e aparente de um objeto e também designa o seu aspecto interno e essencial. Este aspecto da forma está mais vinculado ao sentido metafísico, isto é, concebido "[...] como a natureza essencial de uma coisa separada de sua matéria" (ZATERKA, 2012, p. 683). Aquele aspecto, por sua vez, está vinculado ao sentido físico, designando assim o ordenamento e a padronização observados nos fenômenos naturais, por meio das modificações corpóreas e materiais; nas palavras de Luciana Zaterka (2012, p. 683), trata-se da "[...] forma como a configuração física característica dos seres e das coisas, como decorrência da estruturação de suas partes". Deste modo, Francis Bacon é um grande crítico da concepção metafísica de forma, que prevê a separação entre o inteligível e o sensível - concepção presente 
tanto na metafísica platônica quanto na filosofia primeira de Aristóteles. No entanto, ele se inclina a aceitar, em partes, o sentido físico de forma. Jesus Reynés (2009, p. 290) crê que há um ponto em comum entre Aristóteles e Francis Bacon no que se refere à questão da relação entre o humano e a natureza: ambas concepções do que é o ser humano partem da capacidade de produzir processos motivados pela técnica para interferir racionalmente na natureza. Também, a mudança, tanto no baconismo quanto no aristotelismo, é uma característica sempre presente nos seres naturais. A principal propriedade das coisas naturais, na filosofia da natureza dos dois pensadores, está no fato de tais coisas terem a capacidade de se alterarem por si, sem haver um outro que seja responsável pela mudança, segundo Reynés (2009, p. 292): “Neste sentido, quando falamos de algo natural, nós estamos nos referindo ao que é por causa de si”. No entanto, Aristóteles não explica diretamente a distinção entre o que é natural e o que é artificial, mas apenas deixa claro que os seres naturais se alteram pelo movimento (kinesis), causado por si ou causado por outro.

Sobre esta diferenciação entre os seres que se alteram por si e que se alteram pela ação de outro, diz Aristóteles, na Física (II, 1, 192b8-14):

Algumas coisas são por natureza (esti physei), outras por outras causas (allas aitias). Por natureza, os animais e suas partes, as plantas e os corpos simples (ta hapla ton somaton) como a terra, o fogo, o ar e a água - pois dizemos que estas e outras coisas semelhantes são por natureza. Todas estas coisas parecem diferenciar-se das que não estão constituídas por natureza, porque cada uma delas tem em si mesma um princípio de movimento e de repouso (arkhen ekhei kineseos kai staseios).

Aqui, Aristóteles não explica o que é a natureza em sua definição pura e isolada, mas faz uma caracterização descritiva dos elementos e compostos naturais, cujo princípio está na capacidade de entrar em movimento ou de entrar em repouso. Um animal e uma planta não são coisas feita por outros, existentes por conta de um agente externo que tem domínio sobre a sua produção; são coisas decorrentes de processos 
naturais, que está na característica interna destes corpos. Um animal e uma planta existem porque o processo reprodutivo que os gerou é um processo interno da natureza das espécies.

Dito que physis e tekhne são dois princípios (arkhai) das coisas (ÉVORA, 2005, p. 128), a natureza é o principal referencial na divisão dos seres, sendo estudada tanto na perspectiva da forma quanto na perspectiva da matéria (Física II, 2, 194a12). A matéria, para Aristóteles, é tudo aquilo que está sujeito ao movimento. Trata-se do objeto principal do filósofo da natureza. E a questão da forma? Neste caso, Fátima Évora (1995, p. 128) destaca que os corpos naturais possuem características que são pertinentes às formas matemáticas, ou seja, “[...] os corpos naturais também têm superfície e sólidos, bem como comprimento e pontos, a respeito dos quais o matemático faz o seu estudo". Neste caso, a diferença entre o físico e o matemático é que o primeiro considera as formas em conjunto com a matéria e o segundo considera as formas como separadas da matéria.

O conceito aristotélico de natureza é consubstancial em relação ao conceito de movimento. Basicamente, é por conta do movimento (kinesis) que as coisas na natureza estão submetidas à mudança (metabole): “[...] um corpo em movimento não só muda em relação aos outros corpos, mas, ao mesmo tempo, está ele próprio submetido a um processo de mudança. E este processo exige a ação contínua e direta de uma causa" (ÉVORA, 2005, p. 130). ${ }^{3}$ Além disso, as coisas da natureza são dotadas de uma potencialidade e de uma atualidade. Esta parelha é um pressuposto fundamental na física aristotélica. A potência ${ }^{4}$ é, em uma

\footnotetext{
${ }^{3}$ Vale destacar que, segundo Fátima Évora (2005, p. 130), o conceito de movimento na física antiga e medieval - inteiramente construída a partir do aristotelismo - sofre uma grande transformação na mecânica galileano-cartesiana, no período da modernidade: "De acordo com a mecânica moderna, o movimento não mais corresponde a um processo de mudança, como ocorre na dinâmica aristotélica, mas é um estado inteiro e absolutamente oposto ao repouso, o outro estado, e como tal não necessita de uma causa para mantê-lo".

${ }^{4} \mathrm{O}$ conceito de potência enquanto constituinte de um ser é tratado de diversas maneiras na obra de Aristóteles. Examinar profundamente este conceito seria inviável neste artigo, mas será indispensável apontarmos algumas características principais.
} 
de suas acepções, uma capacidade de um corpo natural de exercer uma ação ou padecer devido a uma ação. Por outro lado, o ato ${ }^{5}$ é a simples realização de uma capacidade de exercer uma ação ou a efetivação do padecimento de uma ação. O movimento, por sua vez, é o que torna possível a transição da potencialidade para a atualidade, e vice-versa (Física III, 1, 201a9). Claro, existem inúmeras sutilezas que não caberia discutir agora, pois basta entendermos que o movimento é um partícipe essencial aos processos naturais. Este é um aspecto em que a filosofia da natureza de Francis Bacon e de Aristóteles se dialogam.

Aristóteles define potência, a partir de dois ângulos, na Metafisica IX, 1: "De fato, (1) existe uma potência de padecer (pathein) a ação, que é, no próprio paciente, o princípio de mudança passiva (arkhe metaboles) por obra de outro ou de si mesmo enquanto outro; e (2) existe uma potência que é capacidade de não sofrer mudanças para pior, nem destruição pela ação de outro ou de si enquanto outro por obra de um princípio de mudança" (1046a12-14, p. 395-7). Sem investigarmos a fundo as características destes dois ângulos conceituais, veremos rapidamente o que cada um significa no contexto desta citação. No primeiro sentido, podemos dizer que o ser carrega em si um princípio de mudança e de padecimento, ou seja, a capacidade de ser afetado e, por conseguinte, de ser modificado. Este padecimento pode ser causado pela ação de um outro ser ou pela ação do mesmo ser (como, por exemplo, a capacidade de aprender e o processo de aprendizado intelectual nos humanos). No segundo sentido, podemos conceber a potência como a disposição do ser em se preservar diante da ação de outro ser ou de si mesmo (como, por exemplo, a tendência dos seres vivos em preservarem as suas próprias vidas). Embora seja um conceito complexo e cheio de nuances por toda a obra de Aristóteles, valemos da deixa do filósofo, concluindo que "Em todas essas definições está contida a noção de potência em sentido originário" (tes protes dynameis logos) (1046a15, p. 397).

${ }^{5}$ Igualmente complexo e cheio de nuances, a noção de ato em Aristóteles é examinada em correlação com o conceito de enteléquia (entelekheia) - que dispensaremos aqui - e de movimento (kinesis), na Metafísica IX, 3: "O termo ato, que se liga estreitamente ao termo enteléquia, mesmo que se estenda a outros casos, deriva sobretudo dos movimentos: parece que o ato é, principalmente, o movimento" (1047a30-1, p. 403). Se a potência é definida originariamente como um princípio de mudança do ser, $\mathrm{o}$ ato é que faz, efetivamente e através do movimento, este princípio ser realizado. Recorreremos a um exemplo do próprio Aristóteles pare entender o que é movimento para não incursionarmos nas problemáticas que envolvem este conceito igualmente complexo: enquanto humanos, temos a potência de caminhar e de sentar; esta potência entra em atividade através do movimento que nos leva, efetivamente, a caminhar ou a sentar. 
Arigor, a dinâmica aristotélica, entre os fatores mais importantes, opera como um conjunto de maneiras para explicar a locomoção, a alteração qualitativa (por exemplo, se algo está quente ou frio) e a alteração quantitativa (por exemplo, se algo cresce ou diminui em matéria ou volume) (ÉVORA, 2005, p. 132). Por sua vez, o conceito de mudança possui um significado mais amplo, visto que é uma forma de explicar a geração e a corrupção das coisas, algo que escapa ao arcabouço do conceito de movimento. A alteração qualitativa, quantitativa e o movimento local são mudanças acidentais, visto que não alteram o ser (ousia) das coisas (ÉVORA, 2005, p. 133). Logo, todo movimento na natureza correspondem ao processo de mudança acidental, mas nem toda mudança é movimento, pois este - tomado isoladamente - não explica a geração e a corrupção dos seres.

Por outro lado, dito o que seriam as principais características dos seres naturais, prossegue Aristóteles (Física II, 1, 192b14-23) com a descrição dos seres não-naturais:

Pelo contrário, uma cama, um vestuário ou qualquer outra coisa de gênero semelhante, enquanto que as significamos em cada caso por seu nome e enquanto são produtos da arte [da técnica] (tekhne), não tem em si mesmas nenhuma tendência natural à mudança (metaboles); mas, enquanto que, acidentalmente, sejam feitas de pedra, de terra ou de uma mescla delas, e somente a este respeito, o têm. Porque a natureza é um princípio e causa do movimento ou do repouso na qual a coisa pertence primariamente e por si mesma, não por acidente (kata symbebekos).

Aqui, Aristóteles está tratando do princípio e da origem das coisas feitas mediante o exercício da técnica. Enquanto as coisas naturais existem a partir de um princípio de movimento e repouso presente nelas mesmas, as coisas artificiais só existem mediante a ação humana sobre as coisas naturais, como, por exemplo, uma estátua de pedra. A pedra em si mesma é um objeto natural, mas a forma ou a figura que é esculpida na pedra é proveniente de uma técnica específica, a saber, a escultura. De nenhuma maneira, a forma da estátua faz parte da essência da pedra 
na qual a figura será esculpida; por esta razão, todo objeto da técnica existe por acidente, ${ }^{6}$ pois o homem destitui o caráter natural do objeto por meio de uma ação produtiva.

No entanto, em relação à filosofia moderna da natureza na esfera do baconismo, o modo de pensar cientificamente na antiguidade não se fundamenta em uma distinção entre o que é natural e o que é artificial. O homem, o anthropos, não possuía, e nem buscava possuir, qualquer força ou poder capaz de alterar a natureza das coisas por completo, diz Jesus Reynés (2009, p. 298):

O mundo dos artefatos não vem senão para completar ou, às vezes, meramente ornamentar a natureza, que somente imperava como única ordem inteligível, e que por isso era uma ordem completamente dada, já estabelecida.

Mesmo que a concepção aristotélica de natureza seja a de um princípio de movimento e repouso de um corpo natural, o estatuto ontológico dela mesma é inalterável. Por conseguinte, o homem não é capaz de suprimi-la em favor da técnica, mas, através dela e do saber produtivo, é capaz de causar modificações ornamentais, sem alterar profundamente a ordem cósmica. Para os antigos, o homem não existe em separado da natureza, visto que é um produto dela. Deste modo, nenhuma ação humana seria capaz de mudar este caráter. No entanto, o desenvolvimento moderno do tema se caracterizou pelo distanciamento

\footnotetext{
${ }^{6}$ Aristóteles apresenta especificamente a noção de acidente (symbebekos), na Metafísica V, 30. A definição geral é: "acidente significa o que pertence a uma coisa e pode ser afirmado com verdade da coisa, mas não sempre nem habitualmente" (1025a14-5). Neste sentido, o acidente é uma ocorrência pontual de um caso observado em alguma coisa, em que este caso não se observa sempre, mas apenas em um dado momento. Trata-se de uma característica atípica que ocorre em algo, não fazendo necessariamente parte da natureza deste algo. Segundo um exemplo elaborado nos trechos a seguir, se cavamos um buraco na terra para plantar uma árvore e nos deparamos com um tesouro, presenciamos um caso acidental, pois não é habitual encontrar tesouros toda vez que nós cavamos na terra (1024a16-8). Portanto, são acidentes todos os acontecimentos que fogem do que é considerado como habitual.
} 
entre os mecanismos naturais e os mecanismos artificiais de geração e produção das coisas.

No âmbito da natureza, em comparação com Aristóteles, Francis Bacon foi um dos personagens filosóficos que buscou investigar até que ponto o homem pode agir ou se submeter a ela. Este interesse, segundo Jesus Reynés (2009, p. 299), parte da insatisfação do filósofo em relação à tese aristotélica da subsunção dos mecanismos artificiais frente aos mecanismos naturais. Evidentemente, esta insatisfação com a metafísica escolástica/aristotélica da natureza serve como mote para a composição do Novum Organum. Uma das questões norteadoras da obra é como o homem pode entender e interagir com a natureza, compreendendo os seus fenômenos e, através desta compreensão, ser capaz de produzir coisas que extrapolam o poder dela em produzi-las.

Desta maneira, o artificial não estaria necessariamente subsumido ao natural, mas seria capaz de alterar profunda e pontualmente a lei e a organização internas de um corpo natural, dando continuidade na dinâmica dos acontecimentos. Isso, claro, leva Francis Bacon, mais do que simplesmente desconsiderar os preceitos metafísicos da filosofia aristotélica, a realocar o conceito de forma, como veremos no decorrer deste trabalho. O filósofo, apesar de pensar a ciência na esfera da modernidade, mantém uma certa identificação ou, ao menos, alguma semelhança com Aristóteles no que concerne à relação entre os mecanismos naturais e os mecanismos artificiais, conforme Reynés (2009, p. 300):

Por exemplo, Bacon, como Aristóteles, reconhece que os movimentos artificiais não têm porquê ir contra o curso da natureza, mas, pelo contrário, são homogêneos uns com os outros. [Bacon] defende que a produção técnica ou artística, enquanto que produção humana, se adicione à natureza.

Portanto, o objetivo da filosofia da natureza de Francis Bacon é reconciliar a natureza com a artificialidade, mas ressaltando a prática humana como transformadora de alguns aspectos da natureza. 


\section{Diferentes perspectivas sobre os novos paradigmas da forma e da doutrina das causas no baconismo}

Afinal, como o conceito de forma se torna o ponto de divergência entre a filosofia da natureza de Aristóteles e Francis Bacon? Na leitura de Jesús Reynés (2009, p. 301), embora haja alguma homogeneidade com a natureza, o aristotelismo prega que todo o produto da técnica ou da arte carece de forma, considerando-a como "[...] a ordem inteligível única que é própria da natureza". Por outro lado, Bacon "flexibiliza" a noção aristotélica de forma, estendendo-a também para o âmbito da arte e da técnica. A rigor, a forma opera tanto como os mecanismos naturais quanto os artificiais, fazendo com que "[...] Bacon [negue] que as coisas naturais e artificiais difiram pela forma" $(2009$, p. 301). Em suma, a forma, no sentido baconiano, ao invés de ser uma ordem inteligível única da natureza, trata-se de uma lei e ordem intrínseca aos mecanismos das coisas naturais e artificiais.

Além do conceito de forma, qual é o papel do conceito de causa na doutrina do conhecimento científico, segundo Francis Bacon? Ressaltamos que a etiologia baconiana é extremamente enraizada na doutrina aristotélica das causas, embora haja algumas críticas e ressalvas quanto ao uso da doutrina para o pensar e o fazer próprio ao modelo baconiano do homem (Novum Organum, II, III, p. 94). Em um caso, investigar a causa material de algum fenômeno da natureza é indispensável para termos o conhecimento científico deste fenômeno. Porém, considerada isoladamente, só teremos um conhecimento imperfeito do acontecimento. O motivo seria a questão da efetividade: devido ao caráter múltiplo e variável da matéria, os efeitos produzidos podem ser diferentes, mesmo quando a causa material é semelhante. Utilizando de um exemplo do próprio Francis Bacon, a brancura e o calor são fenômenos que podem apresentar-se de acordo com as motivações materiais das mais diversas (o calor pode ser originado tanto através do fogo quanto de uma reação exotérmica, causando assim uma alteração material). Por sua vez, para termos um pouco mais de precisão no âmbito do conhecimento científico, precisamos nos ater ao estudo das causas eficientes, que se ocupa em observar o processo de alteração material na esfera da natureza e do experimento científico. 
Na interpretação de Jesús Reynés (2009, p. 301), na filosofia baconiana da natureza, só podemos diferir os mecanismos naturais e artificiais pela causa eficiente, visto que, evidentemente, não é o mesmo agente quem produz as coisas naturais e artificiais. Tanto que a função do homem como ministro e intérprete da natureza é separar e introduzir novas formas e intervir no processo natural das coisas. No sentido metafísico, no aristotelismo, a essência de algo não poderia ser suprimida pela ação humana; no baconismo, o homem tem o poder de alterar a essência. Além disso, a filosofia da natureza baconiana é um tanto avessa à noção de finalidade, como se as formas tivessem de obedecer a um fim pré-determinado. A ação humana ou natural pode, subitamente, alterar os rumos da lei de composição das coisas.

Por estes motivos, Bacon se posiciona contrariamente à doutrina aristotélica da causa final, pois ela representa um obstáculo ao progresso do conhecimento (ZATERKA, 2012, p. 685). A causa final ${ }^{7}$ significa operar com a noção de finalidade para a compreensão dos fenômenos da natureza. Isso significa que há um contraponto com as outras causas, como a eficiente, material e formal. Para compreender as causas material e eficiente, intrinsecamente ligadas aos fenômenos naturais, Luciana Zaterka (2012, p. 686) crê que Bacon propõe um percurso ao estudo da história natural: "Em outras palavras, a proposta baconiana de uma reforma total do conhecimento só é possível se,

\footnotetext{
${ }^{7}$ Para Jesús Reynés (2009, p. 302), Bacon desvincula a causa eficiente da causa formal e final: "[...] o agente se concebe independentemente da forma, justo porque esta não se identifica com o fim". A realocação do conceito de forma que Bacon concretiza na sua filosofia da natureza em relação à concepção aristotélica do termo também se aplica ao substancialismo aristotélico. Na visão de Reynés (2009, p. 303), o substancialismo aristotélico se aplica às coisas compostas de forma e matéria - no caso das substâncias naturais. Bacon, por outro lado, prega que as coisas simples apresentam um potencial transformativo interno, o que traria muito maior dinamicidade, comenta Reynés (2009, p. 303-304): "A consequência, talvez, de maior repercussão deste movimento é a aparição da possibilidade de mudar completamente as espécies de coisas compostas, visto que não possuem essencialidade alguma". Esta nova concepção, que se aproxima quase a um princípio metafísico baseado na dinâmica dos elementos naturais, dá a chancela para o homem em produzir e descobrir compostos variados, deixando em aberto a possibilidade de interferir sobre a natureza. Por conseguinte, fala-se de uma origem de uma nova faculdade humana, fundamentada na descoberta das leis internas das coisas e na possibilidade, através da ação, de alterar estas leis naturais.
} 
original e fundamentalmente, estabelecer-se uma história experimental da natureza". Ora, quais são as características desta nova história natural? São a união entre o conhecimento especulativo e prático, a operação da técnica humana sobre a natureza e as repercussões desta operação em proveito do bem-estar geral. Portanto, a criação de novas naturezas se coloca como paradigma máximo da história natural moderna.

Voltando para o paradigma da forma na filosofia de Francis Bacon, a concepção baconiana de natureza está intimamente interligada com a concepção de forma, visto que os fenômenos e as qualidades sensíveis representam as formas a partir das quais o pensamento científico opera e, por conseguinte, compreende a própria natureza. As formas, em outros termos, representam as coisas mesmas que queremos conhecer (ipsissima res), que nos são manifestas pelo movimento de suas qualidades sensíveis (YSSELMUIDEN, 1906, p. 20), também, "As formas se compõem de um elemento genérico e de diferenças específicas que a limitam" (YSSELMUIDEN, 1906, p. 21). Assim sendo, a forma seria, na concepção baconiana, a realidade objetiva interna a cada elemento natural, que se evidencia pela aparência e pelos fenômenos. Portanto, a forma é a realidade das coisas, e que estariam diretamente conjugadas com o movimento, havendo uma junção entre a causa formal e a causa eficiente.

Para Ysselmuiden (1906, p. 25), a forma e a natureza no baconismo são uma e mesma coisa, salvo na diferença entre o real e o aparente. Se algo na natureza se desenvolve ou se corrompe, a forma acompanha a dinâmica de desenvolvimento e corrupção. Para termos conhecimento da determinação da forma, observamos o elemento geral que se apresenta a vários fenômenos naturais: "Para Bacon, é um princípio - gratuitamente afirmado - que uma forma inclui sempre um elemento genérico" (YSSELMUIDEN, 1906, p. 25). É exatamente neste ponto que o formalismo aristotélico se adapta ao formalismo baconiano, visto que o caráter lógico da formalidade se coloca como um importante recurso para interpretar a realidade concreta, ${ }^{8}$ mas sempre tendo em vista um fim utilitário que é próprio do método científico de Bacon. Logo, o objetivo do método científico baconiano é determinar a convertibilidade

\footnotetext{
${ }^{8}$ Cf. Ysselmuiden (1906, p. 26): "Por exemplo, se nós queremos produzir o calor, será preciso que nós deduzamos a forma do calor de um princípio comum a muitas naturezas que são melhores conhecidos do que a própria natureza".
} 
de um aspecto natural de algo com a realidade concreta como um todo, ou seja, entender até que ponto a natureza de um objeto de interesse do cientista é delimitado pelos aspectos naturais exteriores ao objeto. É aí que a concepção baconiana de forma possui importância capital.

\section{O paradigma das formas segundo Bacon: processo e esquematismo latentes}

Ora, quais são as condições determinantes para a criação de uma nova natureza por parte da ciência e do fazer humanos? Sobre esta questão, Bacon expede uma doutrina a respeito disso: "E nenhum corpo pode ser dotado de uma nova natureza, ou ser transformado, com acerto e sucesso, em outro corpo, sem um completo conhecimento do corpo que se quer alterar ou transformar" (Novum Organum, II, VII, p. 99). Apesar de tratar com críticas e ressalvas a concepção de forma, esta concepção aqui desempenha um papel crucial que, como um aprofundamento da forma enquanto lei do ato, entra o conceito de esquematismo latente (latentis schematismi) que, em suas palavras, designa as "[...] propriedades e virtudes específicas das coisas e donde, também, se retiram as normas capazes de conduzir a qualquer alteração ou transformação" (Novum Organum, II, VII, p. 100). Deste modo, a natureza não pode ser configurada como um todo homogêneo, mas sim em um âmbito diverso, variável e com inúmeras peculiaridades relativas às propriedades dos corpos naturais, cujo movimento e mudança seriam o que há de comum em todos os processos naturais.

No entanto, a metodologia dos processos e esquematismos latentes para a compreensão da natureza dos corpos não são suficientes porque não nos fazem conhecer as leis fundamentais e eternas da natureza ou, nos termos da antiguidade, das formas eternas (ZATERKA, 2012, p. 697). Em suma, na concepção baconiana, como o conceito de forma poderia ser interpretado? Como já vimos acima, trata-se da lei e da organização internas de um corpo natural. A partir desta lei e organização, é possível explicar as maneiras como um corpo se organiza de acordo com as circunstâncias naturais (ZATERKA, 2012, p. 698). Entretanto, para atingirmos o conhecimento das formas naturais, precisamos utilizar do método indutivo que, em termos baconianos, consistiria observar atentamente os processos e esquematismos latentes nos fenômenos. $\mathrm{O}$ conhecimento da forma, muito embora esteja no domínio da metafísica, 
está mais atrelado à “[...] constituição interna dos corpos ou dos modos de operação, isto é, das leis" (ZATERKA, 2012, p. 698). Logo, por meio deste procedimento de apreensão das formas, Bacon buscaria aliar a própria metafísica com a filosofia natural. $\mathrm{O}$ diferencial maior entre as duas é que a filosofia natural trata do estudo das causas material e eficiente e a metafísica trata do estudo das causas formal e final.

Deste modo, o conhecimento das formas naturais é o que traz a possibilidade do homem em modificar a natureza (ZATERKA, 2012, p. 699). Francis Bacon se distancia da concepção aristotélica de formas substanciais e separadas da matéria, pois elas não refletem necessariamente o caráter corpóreo e material da natureza. A forma, para Bacon, deve ser necessariamente conforme a natureza. Neste âmbito, diante da finitude da própria natureza, as formas não são infinitas e refletem a organização essencial única dos corpos. Por outro lado, a finalidade da capacidade do ser humano em conhecer a natureza é mais atrelada à sua modificação do que ao conhecimento da forma. Isso faz com que a concepção baconiana de conhecimento seja mais focada na operação e no processo, deixando de “[...] ser necessário alcançar o conhecimento de essências ou de formas substanciais" (ZATERKA, 2012, p. 700). Em conjunto, podemos pensar o conhecimento das formas, em sua concepção baconiana, de acordo com a tríade formada pelo processo e esquematismo latente dos corpos, a causa material e eficiente dos fenômenos naturais e a lei e organização internas de tais corpos. Portanto, o conhecimento das formas reside na relação entre os arranjos invisíveis dos corpos e as qualidades e ações dos mesmos (ZATERKA, 2012, p. 701).

No baconismo, o procedimento científico de compreensão dos fenômenos da natureza não abandona os procedimentos lógicos de instrução do raciocínio, pois raciocinar é essencial para a descoberta e interpretação dos fenômenos da natureza. Por sua vez, o grande problema que Bacon via nos procedimentos lógicos, como o silogismo, é inseri-los sobre a natureza, como se os princípios lógicos detivessem de alguma primazia sobre os princípios da natureza, diz Ysselmuiden (1906, p. 27): “[...] na física, onde se trata de abarcar a natureza das coisas e não de comprimir de perto um adversário, a verdade nos escapa quando nós pretendemos silogisticar". Mas, no momento em que o silogismo é tirado de cena, como a indução toma lugar como o procedimento racional adequado para conhecer a natureza? A indução, ao contrário do silogismo, não opera através da mediação de termos e palavras no processo de 
conhecimento, trata-se de um contato imediato do nosso intelecto com a natureza: "Por um só e mesmo ato do espírito, nós apreendemos o que procuramos e julgamos" (YSSELMUIDEN, 1906, p. 28). Isso faz com que a indução, até certo ponto, se aproxime do conhecimento sensível. Por outro lado, na medida em que inserimos a natureza no plano da discursividade através de procedimentos lógicos de mediação, como o silogismo, ela nos escapa, pois, estando a natureza sujeita ao contraditório pelo seu caráter de mudança e alteração, um raciocínio que negue o contraditório é contraproducente para o conhecimento de seus fenômenos.

Em síntese, quais são as etapas que envolvem o método baconiano de investigação da natureza? Jesus Heynés (2009, p. 306) pontua três etapas que devem ser linearmente seguidas: (1) conhecimento das formas simples na natureza, (2) conhecimento dos processos latentes que se encontram na dinâmica natural das coisas e (3) descoberta dos esquematismos latentes nos corpos naturais. Estes três passos correspondem às bases do conhecimento científico de Francis Bacon, baseado também na operatividade livre do homem baconiano em conhecer e alterar a forma dos corpos naturais. No entanto, os dois últimos passos exigem uma atenção maior, visto que (HEYNÉS, 2009, p. 307):

O processo e o esquematismo latentes representam uma maior concreção, um maior apego à obra já constituída, porque se situam onde o curso da natureza e, inclusive, o corpo concreto contam como dados que restringem o número de possibilidades abertas para poder combinar as formas em uma só obra.

Pelas citadas razões, o processo baconiano de investigação científica tem de levar em consideração, rigorosamente, as três etapas, justamente para não deixar de lado a dinâmica de mudança e alteração das formas encontradas na natureza. Em síntese, o processo e o esquematismo latente pressupõe uma certa estabilidade de tais formas, como se o objeto em análise não mais estivessem sob o jugo de forças alterativas.

Se tentarmos caracterizar a filosofia baconiana para além de ser um expoente do empirismo moderno, podemos falar de um reformismo do saber e da lógica, o que justifica a ressignificação de conceitos e operadores lógicos e epistemológicos da filosofia aristotélica e escolástica: "Um dos objetivos principais da reforma do saber é o de submeter o homem ao governo da razão, de subtrair seus comportamentos aos modos e aos 
vícios do raciocínio, à verbosidade inútil, às paixões" (ROSSI, 2006, p. 299). Evidentemente, estamos avaliando o empreendimento da ciência moderna sob um olhar baconiano, visto que esta era também fecunda graças ao advento do método matemático, no sentido de retomada das formas e das leis para a interpretação da natureza, algo bastante difundido por Galileu Galilei (1564-1642).

Este método, por sua vez, era visto por Bacon com uma carga de desconfiança e incerteza, conforme diz Paolo Rossi (2006, p. 303):

Bacon nunca considerou a matemática como um método, mas tendeu a reduzi-la a um simples cálculo, mostrandose indeciso inclusive quanto à sua colocação no âmbito da enciclopédia do saber: ora considerando-a como uma parte da metafísica (ciência da quantidade), ora como um simples apêndice da filosofia natural.

Contrariando os preceitos clássicos da metafísica, a busca da verdade na filosofia baconiana é equivalente a uma busca de melhorias da condição da vida humana, o que confirma o caráter amplamente ético do método baconiano e de sua nova lógica. O método de interpretação da natureza de Francis Bacon se apropria parcialmente da filosofia natural de Aristóteles, mas é também uma apropriação negativa, visto que a concretude da filosofia natural dos antigos é sedimentada a partir de observações e experiências insuficientes para promover o encontro entre o homem e a natureza, a despeito do privilégio da vaidade e da impaciência humanos que designava a metafísica como a forma capital de interpretação da natureza. Portanto, interpretar a natureza não significava para Bacon desprezar os que primeiro pensaram sobre ela, mas garantir o encontro entre o pensamento e a própria natureza. Tudo isso a despeito do vício do pensar sobre a natureza que tornou a própria natureza descolada do pensamento.

\section{Referências}

ARISTÓTELES. Física. Introdução, tradução e notas de Guillermo R. de Echandía. Madrid: Editorial Gredos, 1995.

ARISTÓTELES. Metafísica: volume II. Ensaio introdutório, texto grego com tradução e comentário de Giovanni Reale. Tradução de Marcelo Perine. São Paulo: Edições Loyola, 2015. 
BACON, Francis. Novum Organum ou Verdadeiras indicações acerca da interpretação da natureza/Nova Atlântida. Tradução e notas de José Aluysio Reis de Andrade. São Paulo: Abril Cultural, 1979.

ÉVORA, Fátima Regina R. Natureza e Movimento: um estudo da física e da cosmologia aristotélicas. Cadernos de História e Filosofia da Ciência, Campinas, Série 3, v. 15, n. 1, p. 127-170, jan.-jun. 2005.

PANTELIA, Maria. Thesaurus Linguae Grecqae. Irvine: University of California, 2014. Disponível em: http://stephanus.tlg.uci.edu/. Acesso em: 8 abr. 2021.

REYNÉS, Jesús Hernández. Lo natural y lo artificial en Aristóteles y Francis Bacon: Bases para la tecnología moderna. Ontology Studies, Barcelona, n. 9, 2009, p. 289-308.

ROSSI, Paolo. Francis Bacon: da magia à ciência. Tradução de Aurora Fornoni Bernadini. Londrina: Eduel; Curitiba: Editora da UFPR, 2006.

YSSELMUIDEN, G. L'inducion baconienne. Revue Néo-Scolastique, [S.l.], $13^{\circ}$ année, n. 49, p. 18-31, 1906. DOI: https://doi.org/10.3406/ phlou.1906.1920.

ZATERKA, Luciana. As teorias da matéria de Francis Bacon e Robert Boyle: forma, textura e atividade. Scientiae Studia, São Paulo, v. 10, n. 4, p. 681-709, 2012. DOI: https://doi.org/10.1590/S167831662012000400004 .

Recebido em: 14 de janeiro de 2021.

Aprovado em: 9 de março de 2021. 